\title{
Abbreviations and Note on Transliteration
}

EI2 Encyclopedia of Islam, 2nd edition, ed. P. Bearman, Th. Bianquis, C. E. Bosworth, E. van Donzel and W. P. Heinrichs (Leiden: Brill, referenceworks.brillonline.com).

EI3 Encyclopedia of Islam, 3rd edition, ed. Kate Fleet, Gudrun Krämer, Denis Matringe, John Nawas and Everett Rowson (Leiden: Brill, referenceworks.brillonline.com).

This book follows the current British system of Arabic-English transliteration, used by the Encyclopedia of Islam 3, for the majority of technical Arabic terms and Berber terms in Arabic. In accordance with Edinburgh University Press guidelines, place names and personal names are rendered with markers for hamza (') and 'ayn (') but no other diacritics, except in the Index where they are fully vocalised. Similarly, names of authors and book titles transliterated from Arabic are fully vocalised in the Bibliography. Words that are now common in English and can be found in English dictionaries, such as amir, imam and jihad, are not vocalised or italicised. Place names present a particular problem in the Maghrib in that many now have common French, Spanish or English forms. In the case of Iberia, the Arabic place names of the past, sometimes themselves transliterated from Latin or Romance, now often have common Spanish forms. It has therefore proved impossible to be entirely consistent. Where a common English form of a name exists, such as Tangier or Algiers, I have used that in preference to transliteration or other European forms of the name. Where the Spanish or French form is widely used, I have adopted that, Córdoba and Tlemcen, for instance. In the case of less well-known destinations in the Maghrib, those whose names are quite different in Arabic and European languages, or have changed over time, I have transliterated the names from Arabic, for example, Qasr al-Majaz rather than Ksar es-Seghir, Ribat al-Fath rather than Rabat, Bijaya rather than Bougie. I have provided a list of place names giving both their common European and vocalised Arabic forms as an appendix which readers may consult if they wish. 

For Tshiami 


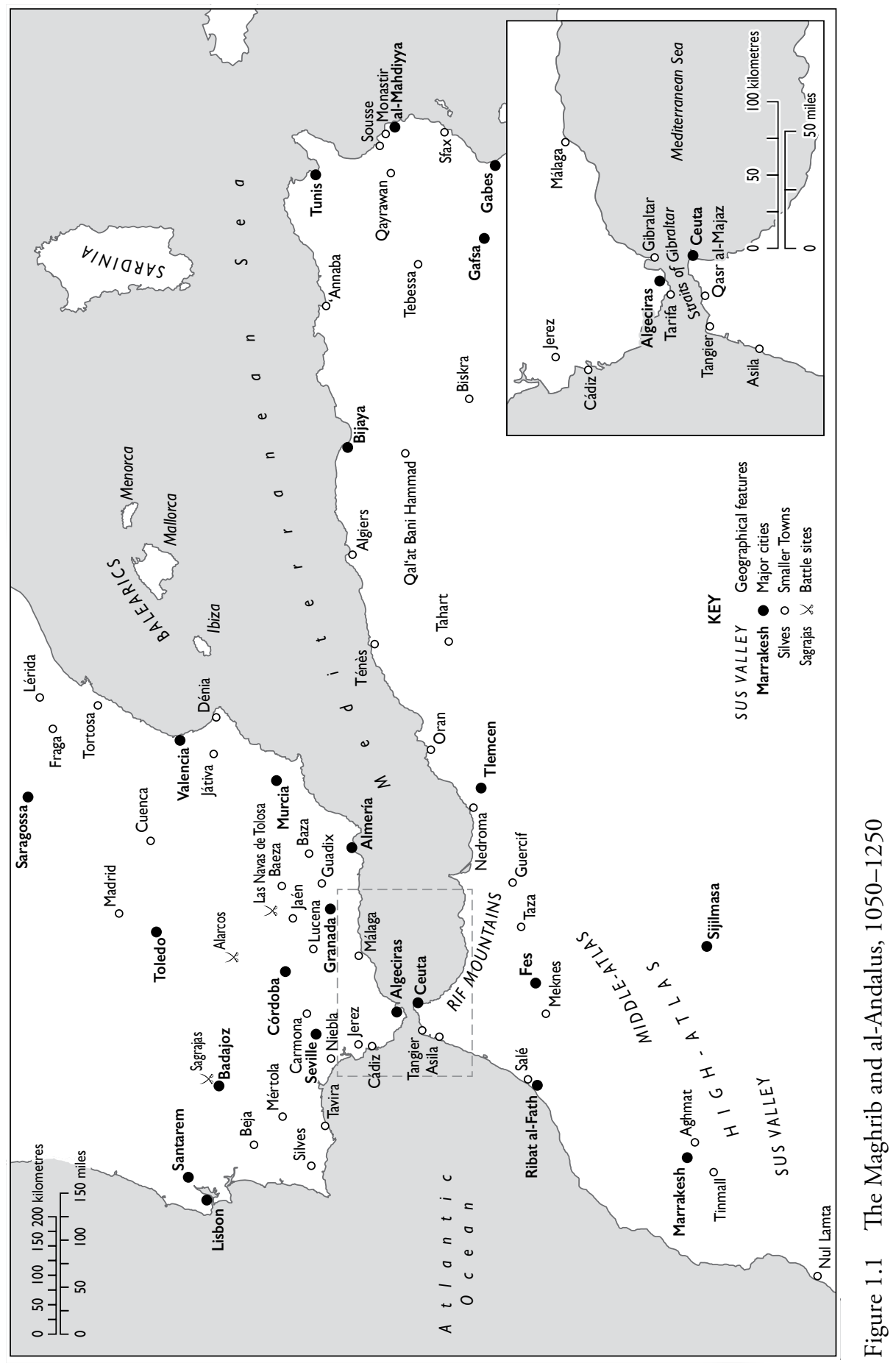

